\title{
LETTERS
}

\section{Illegal killing of birds in Europe continues}

Antoni Margalida, Rafael Mateo

The European Union has enacted several legislative directives in an effort to halt the illegal killing of wildlife. The Environmental Crime Directive requires EU member states to address the killing and trade of protected species and to put an end to the substantial losses of habitats that form the Natura 2000 network of protected areas. The European Union has also signed on to international conventions on wildlife crime. Despite these global efforts to protect biodiversity, illegal killing and trade of birds in the European Union continues unabated. Policy-makers must prioritize the protection of birds and other wildlife by recognizing that the current legislation is ineffective and developing an improved strategy.

The current EU legislation falls short in several ways. First, the final goal of most environmental regulations is to protect and benefit humans, not to conserve the environment in which both humans and wildlife live. Second, the legislation is not enforced, allowing countries to flagrantly flout the law. For example, the Spanish government authorized the capture of 1.7 million finches between 2013 and 2018, presumably to ensure a stock of captive-bred birds in case the ban on trapping was enforced in the future. Third, decentralized systems in countries such as Spain allow a lack of legislative compliance. In the case of illegal poisoning, 10 of the 17 Spanish autonomous regions still lack action plans and invest little in human and economic resources or conservation programs. Spain's lack of commitment shows; in just one of the country's reference laboratories for toxicological analyses, a total of 892 cases of illegal poisoning were diagnosed between 2004 and 2018, including threatened species such as Spanish imperial eagles, cinereous vultures, Egyptian vultures, and red kites. Fourth, legal loopholes allow countries to disregard the legislation. Because such loopholes allow hunting of migratory birds in 26 Mediterranean countries, 11 to 36 million birds are killed illegally every year while migrating through the region.

To ensure that reintroduction and conservation projects are effective, illegal activities that threaten birds must be halted. The first step should be the enforcement of hunting and environmental laws, accompanied by educational policies. Local, regional, and national governments in EU member states can reduce illegal activities by strengthening penalties, standardizing implementation, and increasing controls in the field. Mobilizing long-term funding to tackle wildlife crime is also imperative. 